\title{
Quasi-Static Cyclic Tests on Masonry Spandrels
}

\author{
Katrin Beyer, ${ }^{\text {a,c) }}$ M.EERI, and Alessandro Dazio, ${ }^{\text {b,c })}$ M.EERI
}

This paper presents the results of an experimental campaign on masonry spandrels. Within this campaign, four masonry spandrels were subjected to quasi-static cyclic loading. Two different spandrel configurations were tested. The first configuration comprised a masonry spandrel with a timber lintel, and the second configuration, a masonry spandrel on a shallow masonry arch. For each configuration, two specimens were tested. The first was tested with a constant axial load in the spandrel, while for the second specimen, the axial load in the spandrel depended on the axial elongation of the spandrel. This paper summarizes the properties of the four test units, the test setup, and the most important results from the experiments, documenting the failure mechanisms that developed and the force-deformation hysteresis of the spandrel elements. The paper also presents a mechanical model for estimating the peak strength of masonry spandrels. [DOI: 10.1193/1.4000063]

\section{INTRODUCTION}

In unreinforced masonry (URM) structures, vertical piers are connected by horizontal spandrel elements. Spandrels have been subjected to extensive damage during earthquakes and are often the first elements within a URM building to crack or fail. A typical failure mode of URM spandrels is shown in Figure 1. It shows a building in L'Aquila after the $M_{w}=6.3$ earthquake on 6 April 2009 (Dazio et al. 2009). All the spandrels between window openings have failed in shear and show the characteristic X-crack pattern. In this particular building, the spandrels are heavily restrained by both the relatively wide piers as well as by horizontal tension ties running along the facade embedded in the masonry. A different building is shown in Figure 2, which - like the building in Figure 1-was closely located to the city centre of L'Aquila. In this case tension ties were not present. In addition, the piers were very slender, providing only a minor restraint to the axial elongation of the spandrels. As a consequence, the spandrels failed in flexure by means of wide vertical cracks at both ends of the spandrel. Due to out-of-plane accelerations, one of the spandrels collapsed. This building was a complete loss and was pulled down shortly after the earthquake.

Numerical analyses of masonry walls have shown that spandrel elements can have a significant influence on the global force-deformation characteristics of URM walls (e.g., Cattari and Lagomasino 2008, Milani et al. 2009). In the past, the effect of the spandrel elements was often neglected since experimental evidence on the force-displacement

\footnotetext{
a) Ecole Polytechnique Fédérale de Lausanne (EPFL), 1015 Lausanne, Switzerland

b) EUCENTRE, 27100 Pavia, Italy

c) Formerly Eidgenössische Technische Hochschule Zürich (ETHZ), 8093 Zürich, Switzerland
} 


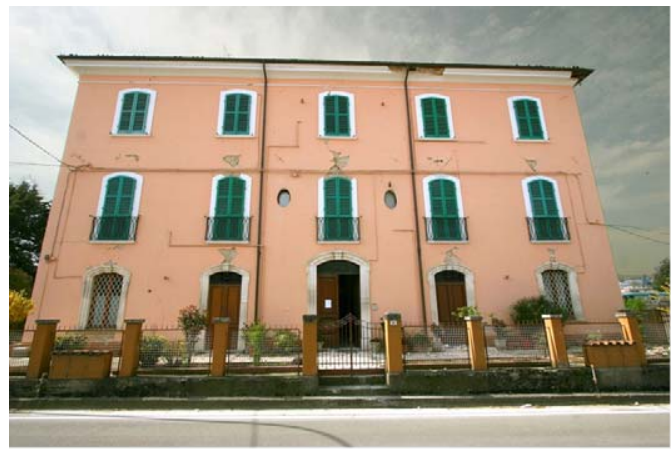

(a)

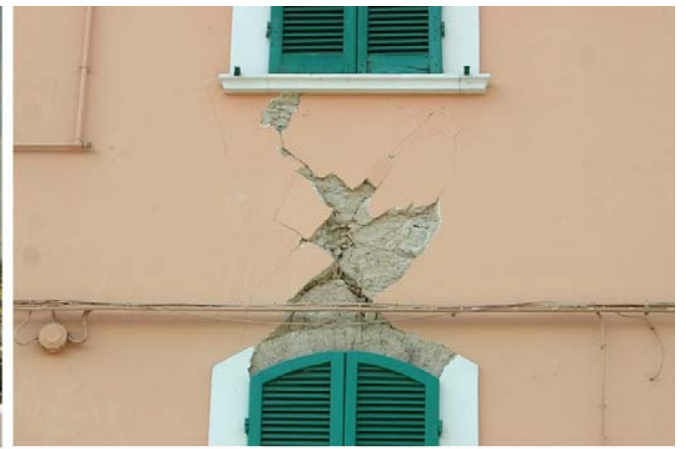

(b)

Figure 1. Shear failure of spandrels with shallow masonry arches in an old URM building after the L'Aquila earthquake on 6 April 2009: (a) Entire building and (b) detail of a spandrel.

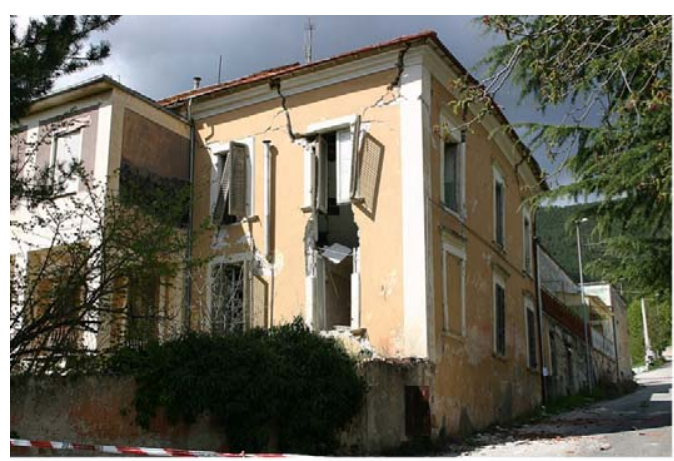

(a)

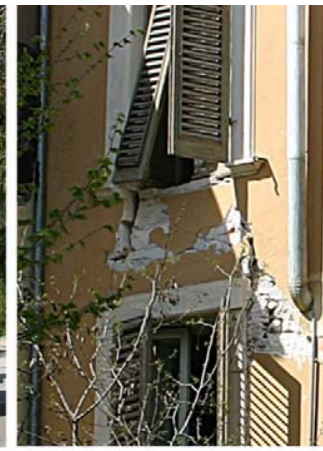

(b)

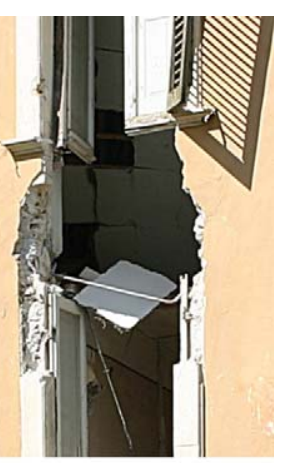

Figure 2. Flexural failure of spandrels in an old URM building after the L'Aquila earthquake on 6 April 2009: (a) Entire building and (b) detail of a spandrel.

characteristics of the spandrel elements was missing. At present, research efforts in Italy at the University of Trieste (Gattesco et al. 2008) and at the University of Pavia (Graziotti et al. 2009) are underway that investigate experimentally the behavior of brick and stone masonry spandrels, respectively. Within the research project carried out by the authors at the ETH Zürich several full-scale test units of different types of spandrels were tested under quasi-static loading (Beyer et al. 2010). This paper summarizes the experimental campaign on masonry spandrels in buildings. These tests included masonry spandrel elements with either a timber lintel or a shallow masonry arch to bridge the opening. The goal of the tests was to provide high-quality experimental evidence as a valuable benchmark for the validation and calibration of numerical and analytical models for URM spandrels with timber lintels and masonry arches. In the following, the properties of the test units, the test setup, and the most important test results are presented. In the final part of this paper, a mechanical 
model for estimating the peak flexural and shear strength of the masonry spandrels is developed, and the predicted strength values are compared to the experimental results.

\section{MASONRY SPANDREL TEST UNITS}

Four masonry spandrel test units were tested (Table 1). Each test unit consisted of two piers and the spandrel element, which were constructed with full bricks featuring dimensions of $250 \times 120 \times 60 \mathrm{~mm}$. The span of the spandrel was $1.18 \mathrm{~m}$, and the height of the spandrel was approximately $1.26 \mathrm{~m}$. The width of the masonry wall was $0.38 \mathrm{~m}$, which corresponds to one and a half times the brick length and included a $1 \mathrm{~cm}$ wide head joint. The bricks were laid in an English bond pattern on both faces of the wall.

Two of the test units (TUA and TUB) had masonry spandrels supported on timber lintels while the other two consisted of spandrels with shallow masonry arches (TUC und TUD). The timber lintel consisted of four timber beams laid next to each other. Each beam was $1.58 \mathrm{~m}$ long and had a rectangular cross section approximately $100 \mathrm{~mm}$ wide and $140 \mathrm{~mm}$ high. The URM arch featured a rise of $120 \mathrm{~mm}$, which corresponds to about $1 / 10$ of the span. A drawing of the test units and photos of spandrel details are given in Table 1. The latter also summarizes the axial stress applied to the piers and the properties of the steel ties that introduced an axial load into the spandrel. In TUA and TUC the axial load

Table 1. Loading scheme, spandrel type, and details of the axial load application for the four test units

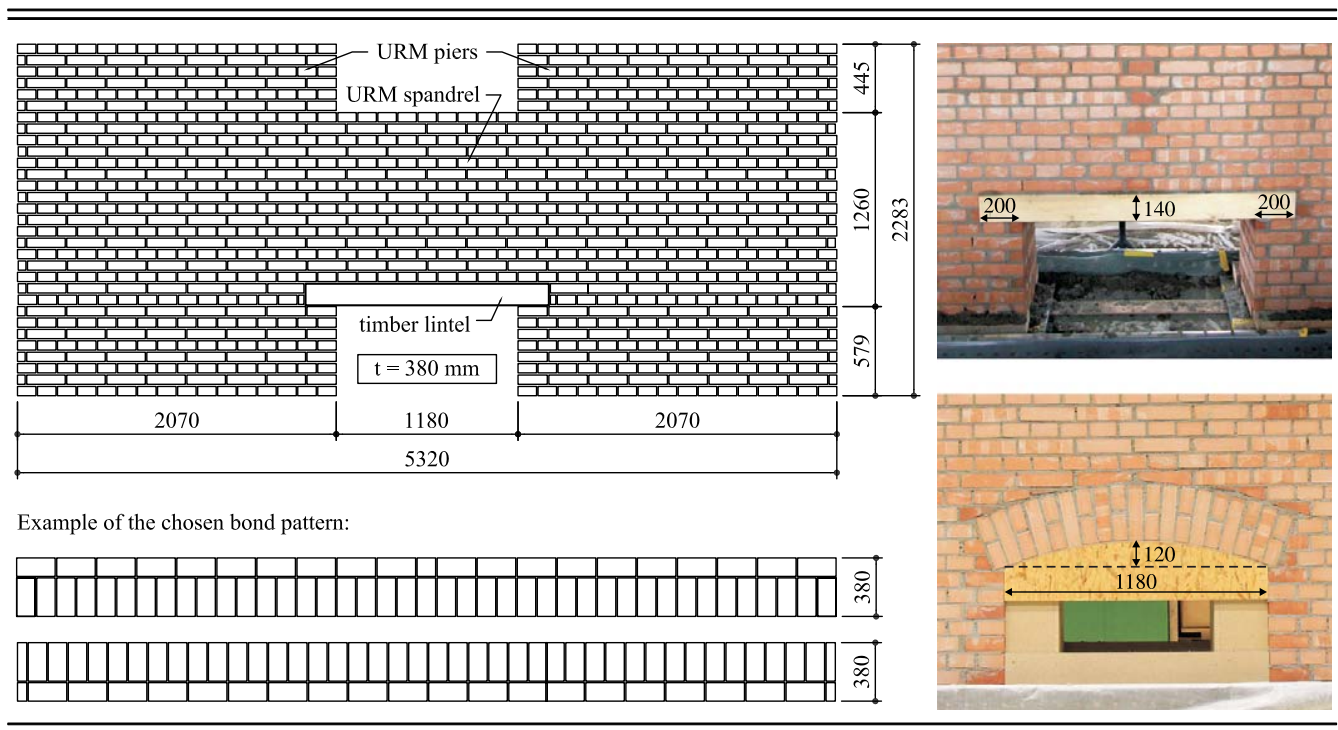

Test Unit Loading Spandrel type Axial stress in piers Axial force in spandrel

\begin{tabular}{lllll}
\hline TUA & Cyclic & Timber lintel & $0.33 \mathrm{MPa}$ & Constant first $80 \mathrm{kN}$, then $40 \mathrm{kN}$ \\
TUB & Cyclic & Timber lintel & $0.33 \mathrm{MPa}$ & Variable, plain bar with low axial stiffness \\
TUC & Cyclic & Masonry arch & $0.43 \mathrm{MPa}$ & Constant $80 \mathrm{kN}$ \\
TUD & Cyclic & Masonry arch & $0.43 \mathrm{MPa}$ & Variable, plain bar with high axial stiffness \\
\hline \hline
\end{tabular}


in the spandrel was provided by means of two horizontal D13 $\mathrm{mm}$ Stahlton rods. The rods were post-tensioned at the beginning of the test, and the force in the rods was kept constant during the test by means of hollow core jacks connected to a load follower (a device which keeps the oil pressure in the hollow core jacks constant throughout a test).

In real buildings, the axial force in the spandrels will depend on the axial elongation of the spandrel and on the boundary conditions provided by the adjacent piers and steel ties, if present. The axial force in the spandrel will therefore vary during seismic loading. While this setup is therefore more realistic for real buildings, a constant axial load is easier to implement in numerical simulations. To study the effect of a varying axial force in the spandrel on the force-deformation characteristics of the spandrel, the axial load in the spandrels of TUB and TUD was provided by means of rods that were slightly pre-tensioned at the beginning and then locked-in. Fixing the length of the rods implied an axial force increase upon axial elongation of the spandrel. In TUB the axial load was provided by means of two D10 mm threaded rods, in TUD two D32 $\mathrm{mm}$ rods were used instead.

\section{MATERIAL PROPERTIES OF TEST UNITS}

Parallel to the quasi-static cyclic tests on the four test units representing spandrels in old buildings, material tests on mortar, brick and masonry were carried out. In addition, for the test units TUA and TUB the timber beams used for the lintels were tested. For TUB, also, tension tests on the threaded D10 mm rods, with which the horizontal restraint was applied and which was designed to yield, were carried out. Details on the material tests concerning specimen preparation, testing procedure and evaluation of the results are given in the test report (Beyer et al. 2010). In the following the most important properties of bricks, mortar, timber and rods are summarized.

The full bricks with the standard dimensions $250 \times 120 \times 60 \mathrm{~mm}$ were new bricks, which are today typically used for the construction of fireplaces. Table 2 presents median values and standard deviations for the density $\rho_{b}$, the E-modulus $E_{b}$, the compressive strength $f_{c b}$ and the tensile strength $f_{t b}$ of the bricks. Density, E-modulus and compressive strength were determined from measurements on whole bricks (Binda et al. 1994). For the E-modulus and the compressive strength single bricks were subjected to compression along their longitudinal axis (Figure 3a). The compressive strength was computed as the maximum force divided by the cross sectional area of the brick. The E-modulus was determined from Demec measurements with base lengths of $150 \mathrm{~mm}$ at approximately $0 \%$ and $33 \% f_{c b}$. The tensile strength was determined from a three-point bending test on brick specimens with the dimensions of

Table 2. Mechanical properties from tests on bricks and mortar (median values and standard deviations)

\begin{tabular}{lcclccr}
\hline \hline Test unit & $\rho_{b}\left[\mathrm{~kg} / \mathrm{m}^{3}\right]$ & $E_{b}[\mathrm{GPa}]$ & $f_{c b}[\mathrm{MPa}]$ & $f_{t b}[\mathrm{MPa}]$ & $f_{c m}[\mathrm{MPa}]$ & $f_{t m}[\mathrm{MPa}]$ \\
\hline TUA & $1880 \pm 30$ & $10.8 \pm 0.9$ & $36.2 \pm 5.3$ & $8.5 \pm 0.5$ & $11.2 \pm 0.3$ & $3.3 \pm 0.3$ \\
TUB & $1880 \pm 6$ & $10.8 \pm 1.6$ & $35.5 \pm 4.6$ & $7.0 \pm 1.6$ & $13.0 \pm 2.8$ & $3.4 \pm 0.6$ \\
TUC & $1840 \pm 28$ & $11.1 \pm 0.7$ & $31.3 \pm 10.0$ & $6.5 \pm 3.7$ & $17.9 \pm 3.3$ & $4.3 \pm 0.3$ \\
TUD & $1840 \pm 52$ & $8.4 \pm 2.5$ & $30.2 \pm 5.3$ & $5.0 \pm 3.4$ & $20.3 \pm 2.8$ & $4.5 \pm 0.4$ \\
\hline \hline
\end{tabular}




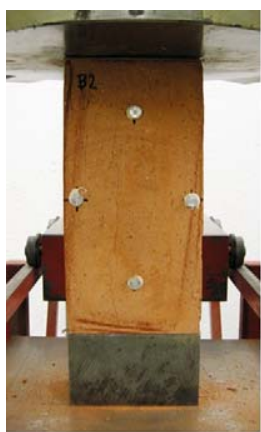

(a)

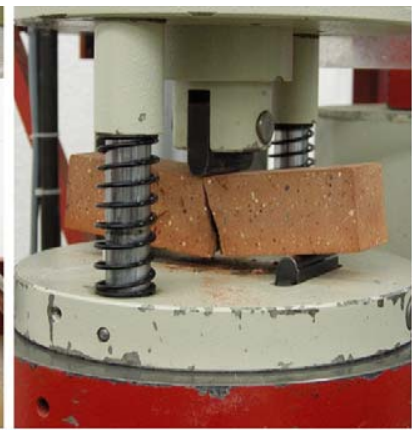

(b)

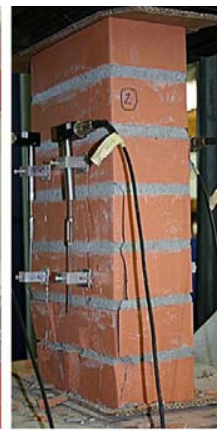

(c)

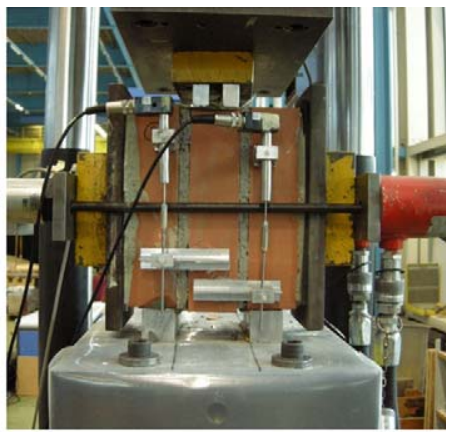

(d)

Figure 3. Material tests: (a) Compression test with Demec measurement points on an entire brick; (b) 3-point bending test on a brick prism; (c) compression test on a masonry prism; and (d) triplet shear test.

$160 \times 40 \times 40 \mathrm{~mm}$ and a free span of $100 \mathrm{~mm}$ (Figure $3 \mathrm{~b}$ ), that is, the same test, which is typically used for mortar samples (CEN 2006a).

The mortar used for the construction of the test units was a standard cement mortar with $280 \mathrm{~kg} / \mathrm{m}^{3}$ cement (CEM II/A-LL 42.5N). To determine the tensile strength $f_{\text {tm }}$ and the compressive strength $f_{c m}$ of the mortar, mortar prisms with dimensions of $160 \times 40 \times 40 \mathrm{~mm}$ were sampled at regular intervals during the construction of the test units. Three-point bending tests with a free span of $100 \mathrm{~mm}$ and cube compression tests were carried out according to EN 1015-11 (CEN 2006a); the results are summarized in Table 2.

In addition to tests on the constituent brick and mortar, compression tests on masonry prisms were carried out (Figure 3c). The properties of the interface between mortar and brick were characterized by means of triplet tests (Figure 3d) according to EN 1052-3 (CEN 2007). TUA and TUB as well as TUC and TUD were constructed pairwise at the same time. For each construction phase only one set of six prisms for compression tests and twelve triplets was constructed and tested. From the compression tests on the masonry prisms the E-modulus $E_{c M}$, the compressive strength $f_{c M}$ and the strain at peak strength $\varepsilon_{c M}$ of the masonry were determined. The results of the compression tests are summarized in Table 3. The first two columns indicate the mortar strength values for $f_{t m}$ and $f_{c m}$ that were obtained from mortar samples during the construction of the masonry prisms. Mohr-Coulomb relationships describing the peak and residual shear strength of the joints are summarized in Table 4.

Table 3. Mechanical properties from tests on masonry prisms (mean values and standard deviations)

\begin{tabular}{lcccccc}
\hline \hline Test units & $f_{c m}[\mathrm{MPa}]$ & $f_{t m}[\mathrm{MPa}]$ & $E_{c M}[\mathrm{GPa}]$ & $f_{c M}[\mathrm{MPa}]$ & $E_{c M} / f_{c M}[-]$ & $\varepsilon_{c M}[\%]$ \\
\hline TUA+TUB & $14.4 \pm 1.9$ & $3.74 \pm 0.44$ & $13.2 \pm 3.5$ & $18.0 \pm 2.0$ & $730 \pm 163$ & $0.21 \pm 0.03$ \\
TUC+TUD & $16.5 \pm 2.5$ & $4.30 \pm 0.17$ & $8.9 \pm 2.8$ & $14.7 \pm 2.6$ & $666 \pm 358$ & $0.25 \pm 0.11$ \\
\hline \hline
\end{tabular}


Table 4. Shear tests: Friction coefficient $\mu$, cohesion $c$, and correlation coefficient $R^{2}$ for peak and residual shear tests

\begin{tabular}{lcccccccc}
\hline \hline & \multicolumn{3}{c}{ TUA + TUB } & & \multicolumn{3}{c}{ TUC + TUD } \\
\cline { 2 - 4 } \cline { 8 - 9 } Mohr-Coulomb relationships & $\mu[-]$ & $c$ [MPa] & $R^{2}[-]$ & & $\mu[-]$ & $c[\mathrm{MPa}]$ & $R^{2}[-]$ \\
\hline Peak stress: $\tau_{\text {max }}=\mu_{\text {peak }} \sigma+c_{\text {peak }}$ & 0.85 & 0.35 & 0.59 & & 0.73 & 0.18 & 0.84 \\
Residual stress: $\tau_{\text {res }}=\mu_{\text {res } 1} \sigma+==$ & 0.78 & -0.01 & 0.92 & & 0.75 & -0.01 & 0.99 \\
Residual stress: $\tau_{\text {res }}=\mu_{\text {res } 2} \sigma$ & 0.77 & 0 & 0.92 & & 0.73 & 0 & 0.99 \\
\hline \hline
\end{tabular}

The timber used for the construction of the lintel of TUA and TUB was tested by means of four-point bending tests with a free span between the supports of $1.0 \mathrm{~m}$ and a distance between the two load application points of $0.3 \mathrm{~m}$. During the tests of the spandrels, the timber lintels remained largely elastic. For this reason only, the E-moduli are reported. A global E-modulus of the tested timber beams was determined from deflection measurements while a local E-modulus was computed from average strain measurements in the region of constant moment. For TUA the global and local E-moduli of the entire timber lintel (considering all four parallel beams) were $6.7 \mathrm{GPa}$ and $12.1 \mathrm{GPa}$, respectively. For TUB the corresponding values were $8.1 \mathrm{GPa}$ and $11.7 \mathrm{GPa}$, respectively.

The D10 $\mathrm{mm}$ threaded rods that were used to apply the axial force in the spandrel of TUB had an effective diameter of $8.9 \mathrm{~mm}$, a stiffness of $E A=10.5 \pm 0.1 \mathrm{kN}$ and a dynamic yield and ultimate tension force capacity of $31.8 \pm 0.7 \mathrm{kN}$ and $35.5 \pm 0.5 \mathrm{kN}$, respectively (CEN, 2006b). The dynamic strength corresponds to the value measured during loading. To obtain the corresponding static values the loading was stopped for two minutes each at strains of $0.5 \%$ and $2.0 \%$ and the drop in strength of the bar was measured. The static yield and ultimate tension force of the threaded rods were $30.7 \pm 0.5 \mathrm{kN}$ and $33.3 \pm 0.2 \mathrm{kN}$, respectively.

\section{TEST SETUP, INSTRUMENTATION, AND LOADING HISTORY}

\section{TEST SETUP}

In the test stand, the test unit stood on two stiff steel beams ("lever beams") that were supported on hinges at the centre line of the piers and connected to servo-hydraulic actuators at their ends (Figures 4 and 5). During testing the two servo-hydraulic actuators were moved with the same velocity in opposite directions. As a result, the two horizontal lever beams rotated and the piers right and left to the spandrel were subjected to the same drifts, which caused the demand on the spandrel. The support of the South lever beam allowed next to a rotation also a sliding movement along the longitudinal axis of the beam. Hence, the test stand did not restrain the axial elongation of the spandrel. To apply an axial load to the spandrel, two horizontal rods introduced an axial force into the spandrel, which was either constant throughout the test (TUA and TUC) or dependent on the axial elongation of the spandrel (TUB and TUD). The position of the rods reflects the typical height of steel rods in real buildings. The two piers were post-tensioned by four vertical 


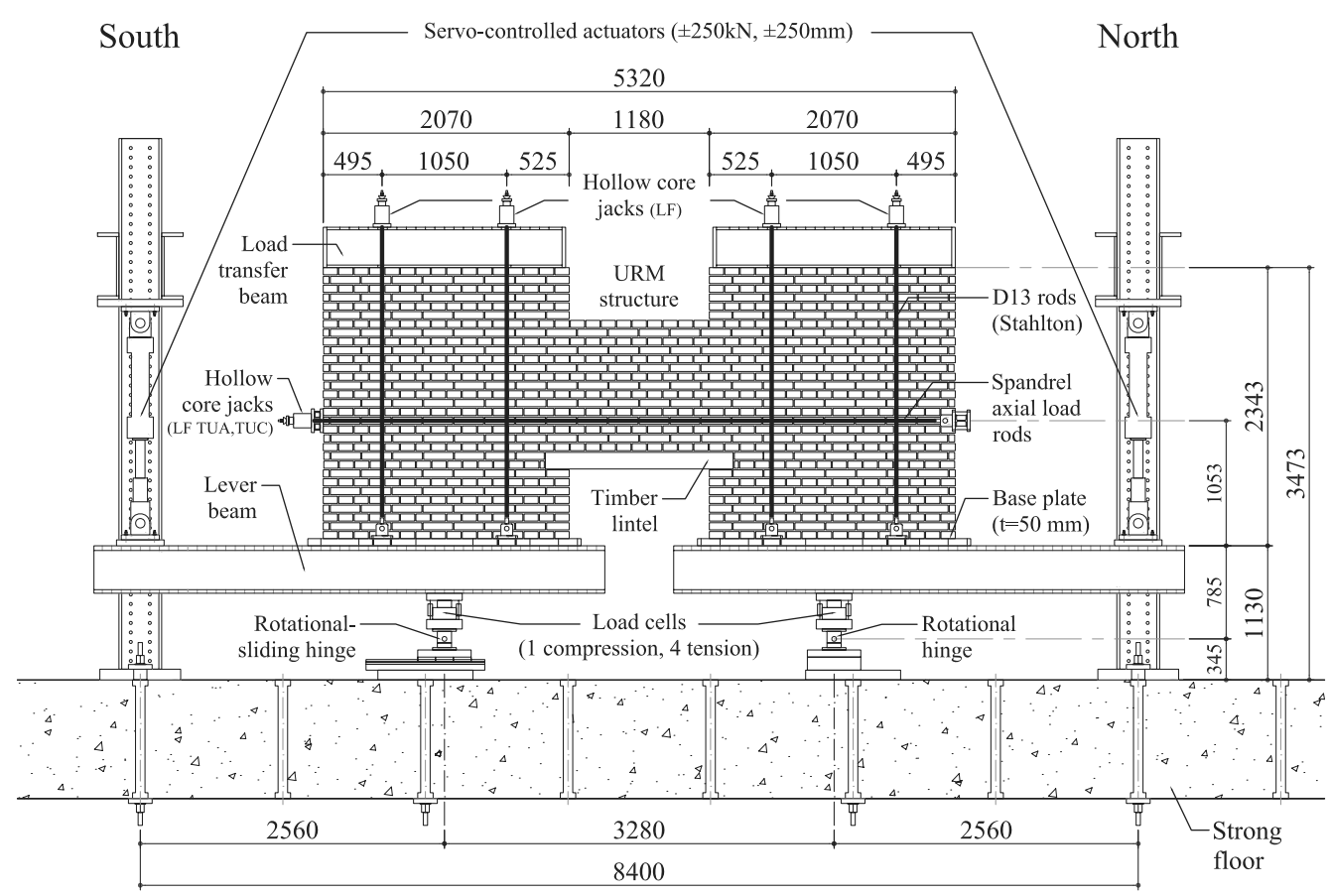

Figure 4. Drawing of the test setup for the masonry spandrel with timber lintel. View from the east without side restraint. All dimensions are in [mm]. (LF $=$ Hollow core jacks connected to load follower, which keeps the oil pressure constant.)

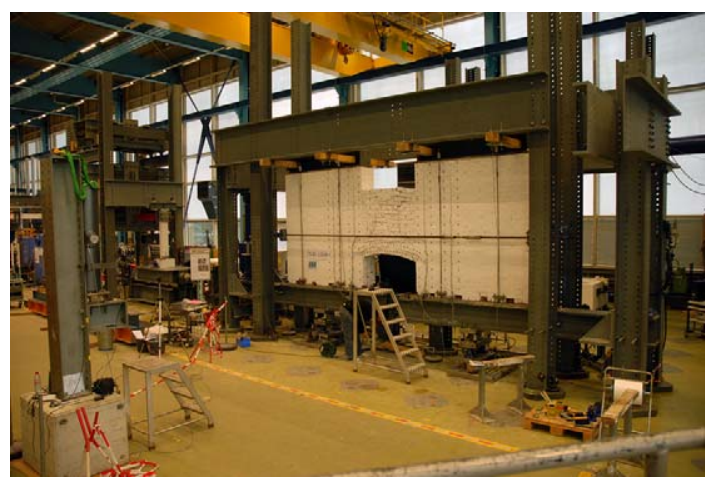

Figure 5. Photo of the test setup. View from the northeast.

rods each. The force in each vertical rod was kept constant throughout the test. The purpose of these rods was to simulate the axial force in piers in real buildings.

Gattesco et al. (2008) and Graziotti et al. (2009) used a test setup for testing masonry spandrels (setup A), which differed from the test setup shown in Figure 4 (setup B). In their 


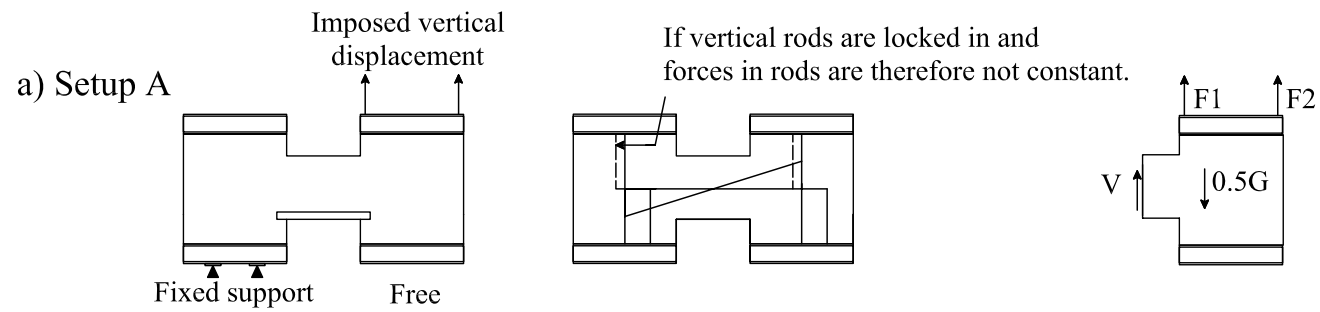

b) Setup $B$ Imposed pier rotations

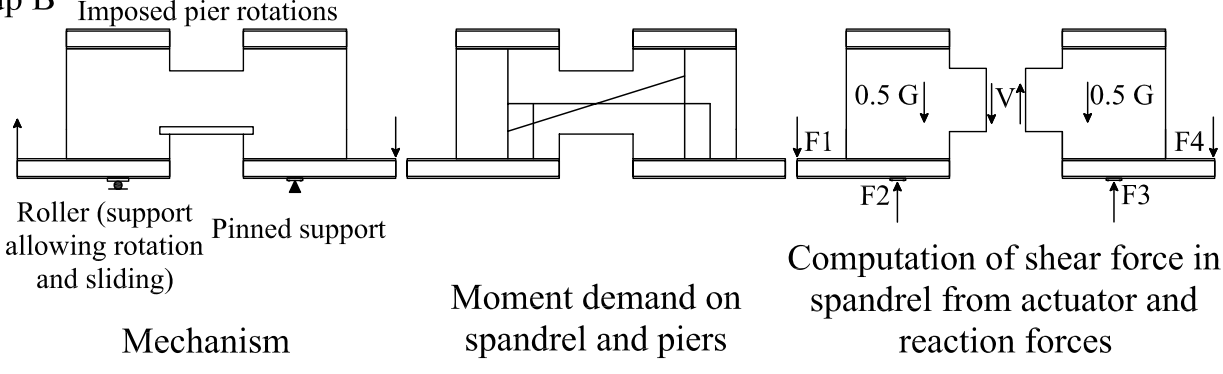

Figure 6. Comparison of two different test setups for spandrel tests: (a) Setup A was used by Gattesco et al. (2008) and Graziotti et al. (2009), while (b) Setup B was adopted in the study presented here.

test setup one pier was fixed on the ground while the other was moved vertically up and down (Figure 6a). Figure 6 shows the moment demand on the piers and spandrel for the two different test setups. Both test setups impose on the spandrel element a linear moment profile, which corresponds to the moment demand on spandrel elements obtained from numerical studies of URM buildings. However, for neither of the two test setups, the moment demand in the piers reflects the moment demand on piers in URM buildings. For this reason, excessive damage to the piers should be avoided by applying a sufficiently large vertical prestress to the piers. A first comparison of the results obtained for test unit M1r by Gattesco et al. (2008) and TUC, which had similar spandrel dimensions as well as similar axial stress levels in the spandrel, revealed that the two test setups yielded similar results in terms of the forcedeformation hysteresis of the spandrel as well as the failure mechanism.

None of the two test setups allows measuring the shear force in the spandrel directly. Figure 6 shows schematically how the shear force in the spandrel can be computed from the measured actuator and reaction forces as well as the weight of the test unit. Test setup B has the advantage that the spandrel shear force can be computed from the left and the right end of the test unit, which allows double checking the measured quantities and determining the weight of the test unit from force measurements rather than volume and density estimates. In addition, the authors considered test setup B advantageous, since a possible sudden loss in pressure in the actuators, would not have caused significant damage to the test unit since the weight of the test unit was supported on the hinges underneath the lever beams. Throughout all tests, the test setup B worked very reliably. 


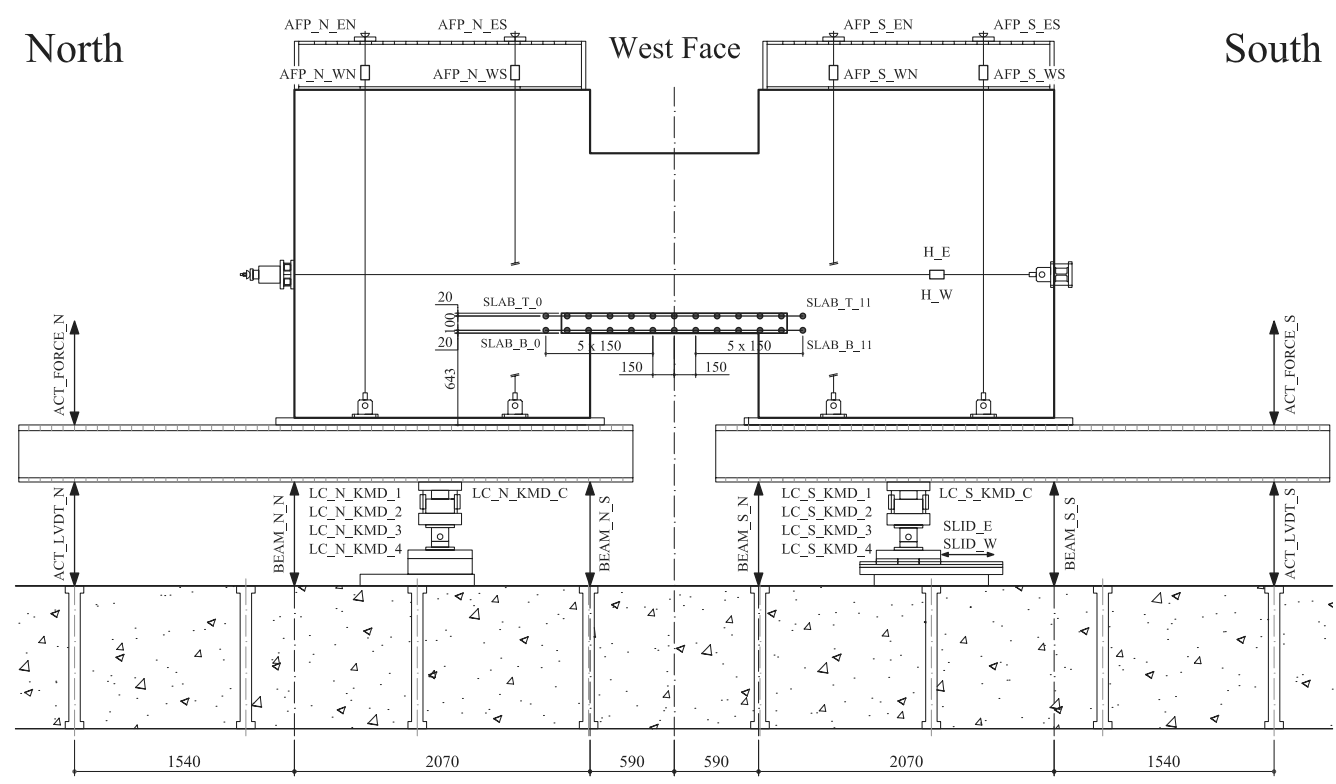

Figure 7. Layout of the hard-wired instruments for masonry spandrels with timber lintel.

\section{INSTRUMENTATION}

Different global and local quantities were measured during testing by means of hardwired instruments. These included (Figure 7): (i) The actuator forces and the reaction forces at the supports of the beams, (ii) global deformation quantities, i.e., the rotation of the lever beams and the sliding movement of the South lever beam and (iii) the forces in the vertical and horizontal rods generating the axial load in the piers and spandrel, respectively. For TUA and TUB also the local deformation of the timber lintel was measured by means of linear variable differential transformer (LVDT) chains running along the top and bottom edges of the lintel's West face. From the measurements of the actuator forces and the forces at the supports the spandrel shear force was computed. The rotation of the piers was measured by the LVDTs mounted underneath the lever beams. For each lever beam the rotation was computed as:

$$
\begin{gathered}
\theta_{N}=\left(B E A M_{-} N_{-} S-B E A M_{-} N_{-} N\right) / d \\
\theta_{S}=\left(B E A M_{-} S_{-} S-B E A M_{-} S_{-} N\right) / d
\end{gathered}
$$

where $d=2.07 \mathrm{~m}$ is the distance between the relevant LVDT. The drift is defined as positive when the piers are displaced towards North (Figure 8). Since the velocity of the actuators was controlled via displacement transducers mounted on the actuators themselves, the actual drifts of the lever beams could differ slightly. This was mainly due to some small backlash 


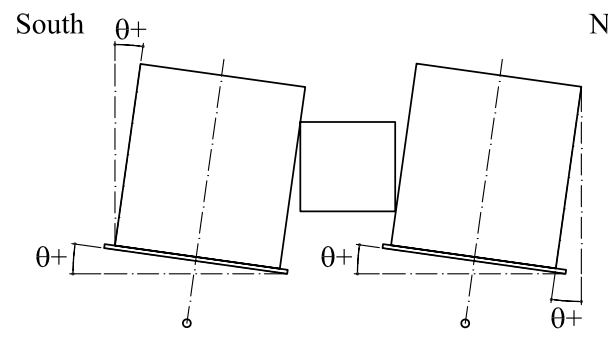

(a) Positive direction of loading Drift towards North

North South

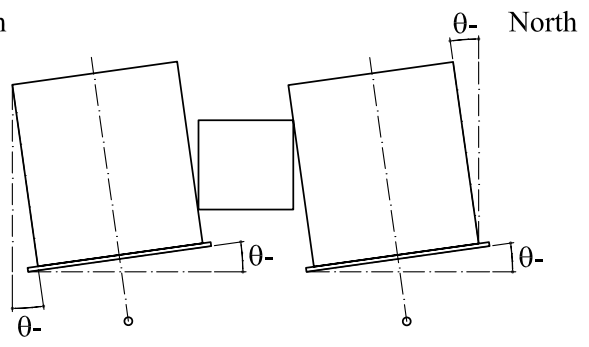

(b) Negative direction of loading Drift towards South

Figure 8. (a) Positive and (b) negative direction of loading. View from the east.

within the actuators' hinges. The final drift was computed as the average rotation of the North and South lever beams:

$$
\theta=\left(\theta_{N}+\theta_{S}\right) / 2
$$

The demand on the spandrel does not only depend on the pier rotations but also on the length of the spandrel. The "spandrel displacement" was computed as (Milani et al. 2009):

$$
\Delta_{s p}=\theta \cdot\left(l_{s p}+l_{\text {pier }}\right)
$$

where $l_{s p}$ is the length of the spandrel and $l_{\text {pier }}$ the length of the pier. For the tested spandrels these lengths were $1.18 \mathrm{~m}$ and $2.07 \mathrm{~m}$, respectively.

Since the test setup did not provide a restraint to the axial elongation of the spandrel, the axial force acting on the spandrel could be computed from the forces in the two horizontal rods:

$$
H_{s p}=H_{-} E+H_{-} W
$$

\section{LOADING HISTORY}

Quasi-static cyclic tests were performed and for each amplitude level two cycles were applied. The considered amplitudes of the half-cycles corresponded to the following nominal drift levels $\theta_{\text {nom }}: 0.025 \%, 0.05 \%, 0.1 \%, 0.2 \%, 0.3 \%, 0.4 \%, 0.6 \%, 0.8 \%, 1.0 \%, 1.5 \%, 2.0 \%$, $2.5 \%, 3.0 \%$. The nominal drift refers to the target drift of a load step. Since the loading was stopped manually, the actual drift at the end of a load step could differ slightly from the target drift. A schematic figure of this loading scheme is shown in Figure 9. A load step corresponds to the peak of one half-cycle of the loading history. The numbering of the drift-controlled load steps commences with LS 2. LS 0 refers to the state before any rotations or forces were applied. Afterwards, the axial load was applied to the piers (LS 1a) and the rods restraining the axial elongation of the spandrel were post-tensioned (LS 1b). At each load step the loading was stopped, cracks were marked and photos taken. 


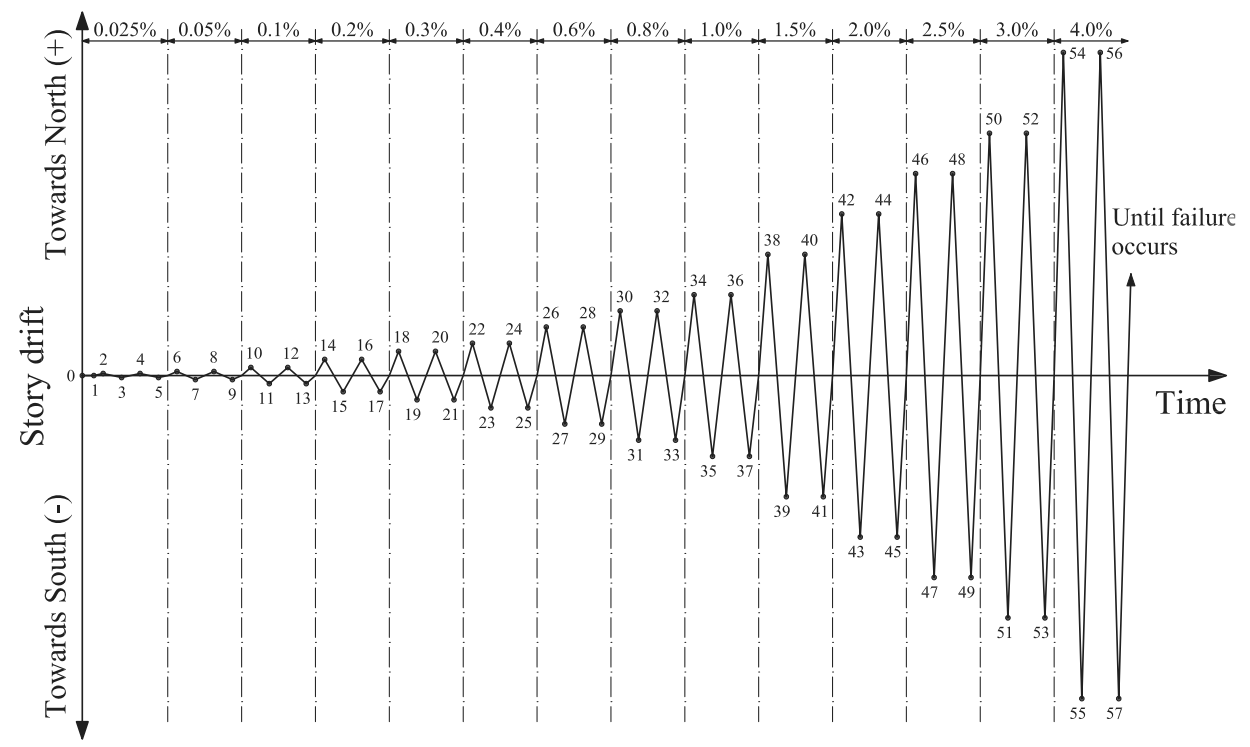

Figure 9. Loading history for quasi-static cyclic spandrel tests.

\section{TEST RESULTS}

In the following the development of the crack pattern, the failure mechanisms, the shear force-deformation and axial force-deformation hysteresis curves of the four test units are discussed. To gain an impression on the state of the spandrel at the ultimate deformation capacity of the adjacent piers, particular attention is given to the state of the spandrel at a pier drift of $0.4 \%$, which is according to EC 8 (CEN 2005) the deformation capacity of masonry piers failing in shear. Note, however, that the relationship between deformation demand on the spandrel and pier drift is not unique but depends on the geometry of spandrel and piers (see Equation 3).

\section{TEST OBSERVATIONS}

During the small cycles of TUA (up to a maximum pier rotation of $0.2 \%$ ) the combination of axial load on the piers and axial load in the spandrel was modified two times. The test was started with an axial stress in the piers of $0.18 \mathrm{MPa}$ and an axial force in the spandrel of $80 \mathrm{kN}$. It was then noted that part of the drift demand imposed by the rotation of the lever beams was absorbed within a base crack of the piers. This deformation was not intended. To eliminate this mechanism, the axial stress in the piers was increased to $0.33 \mathrm{MPa}$. However, even for this stress level, the crack at the base still opened up and therefore, as a second measure, the axial force in the spandrel was reduced to $40 \mathrm{kN}$, which corresponds to an average compression stress in the spandrel of about $0.08 \mathrm{MPa}$. This configuration was used for all cycles with $\theta_{\text {nom }}>0.2 \%$.

Figure 10 shows the crack pattern for pier drifts of $0.4 \%$ and at failure for a drift of $3.0 \%$. At $\theta_{\text {nom }}= \pm 0.4 \%$, for the positive direction of loading (Figure 10a), the spandrel had 


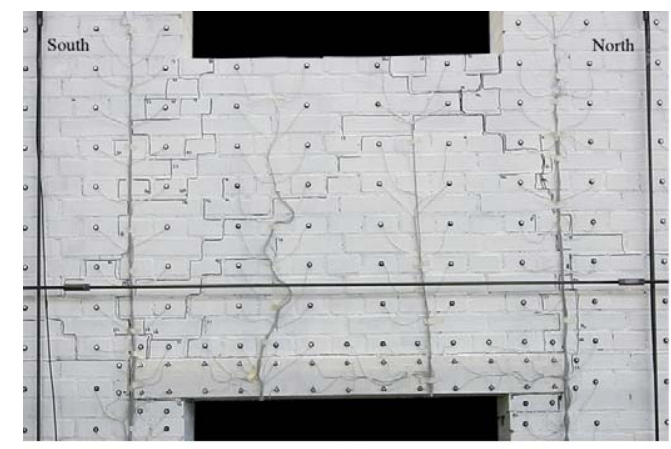

(a)

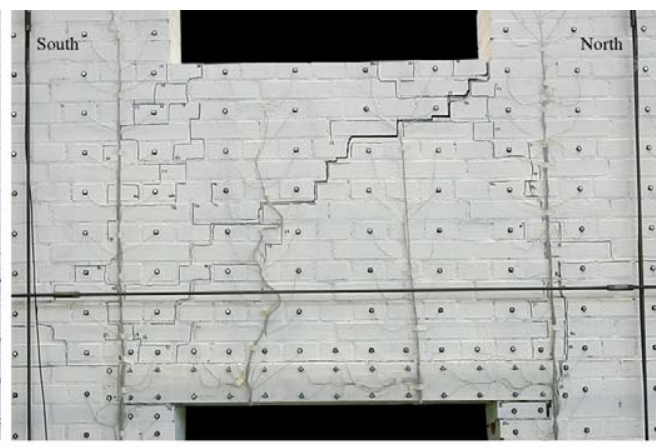

(b)

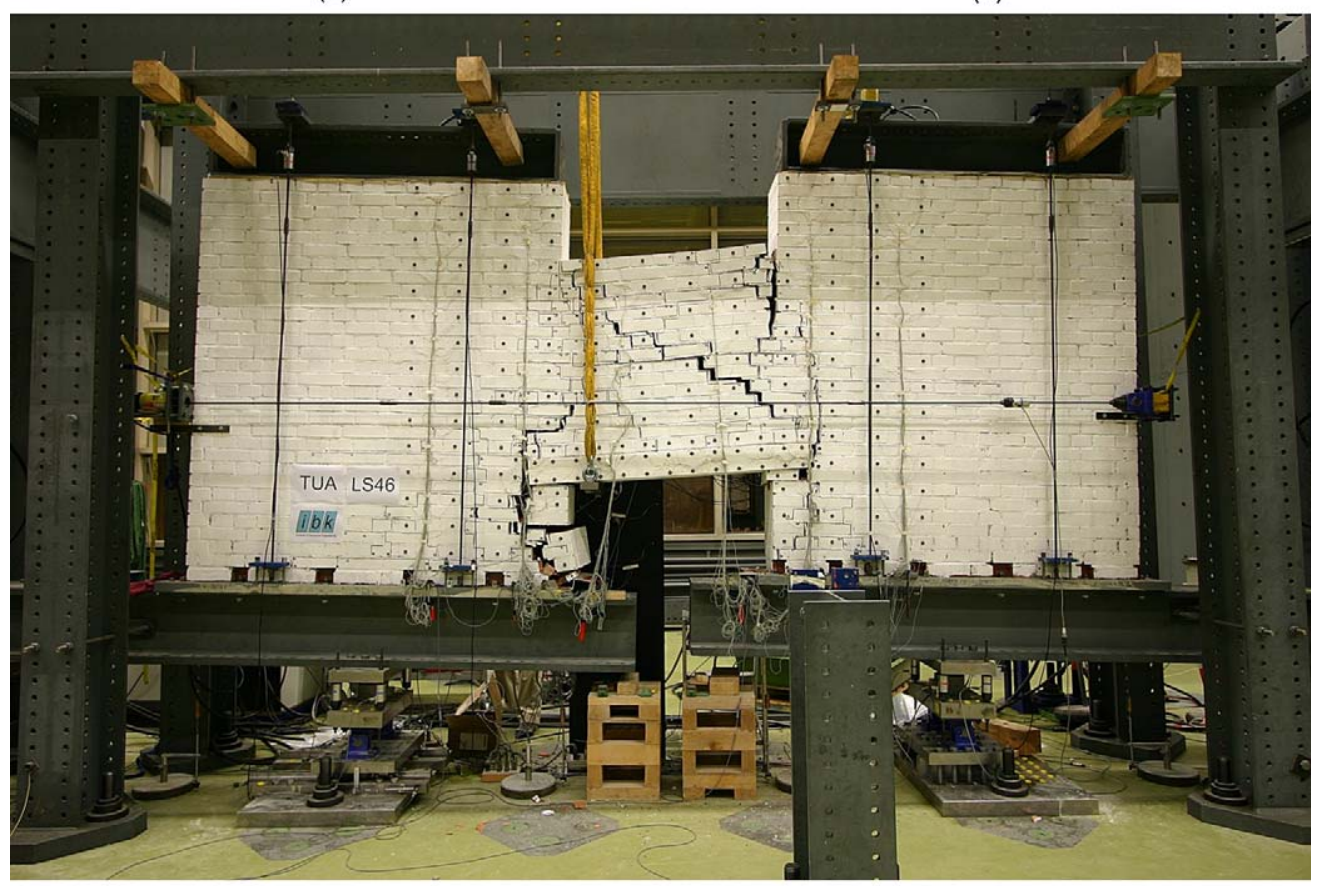

(c)

Figure 10. TUA: Crack pattern at (a) LS $22\left(\theta_{\text {nom }}=+0.4 \%\right)$; (b) LS $23\left(\theta_{\text {nom }}=-0.4 \%\right)$; and at (c) LS 46 (failure of TUA at $\theta=+3.0 \%$ ).

developed a flexural mechanism with vertical cracks at both ends of the spandrel, which reached around the timber lintel. For the negative direction of loading (Figure 10b), most of the deformations were absorbed by a large stair-stepped shear crack, which crossed the entire spandrel. As loading continued, such a diagonal crack developed also for the positive direction of loading. The final crack pattern of the spandrel corresponded to a mixed flexure-shear failure with vertical cracks at the end of the spandrel and shear cracks in the spandrel. The final failure of the test unit occurred for a drift of $3.0 \%$ and was associated 
with the failure of the supports of the timber lintel in the piers (Figure 10c); they rotated inwards due to the horizontal shear stresses caused by the pull-out forces of the timber lintel.

TUB was the first test unit to be tested for which the axial load in the spandrel depended on the axial elongation of the spandrel. In order to straighten the two horizontal rods, the horizontal rods were pre-tensioned to $2.5 \mathrm{kN}$ each at the beginning of the test and then locked-in. The axial stress in the piers, which was applied by the vertical rods, was $0.33 \mathrm{MPa}$ (Table 1). Similar to TUA, the first cracks that developed were flexural cracks at both ends of the spandrel reaching around the ends of the timber lintel. The cracks were rather vertical and passed through several bricks indicating a flexural failure of the spandrel. As a result of the cracking the force in the horizontal rods increased. Figure 11a and $b$ show the cracking state of TUB at a pier drift of $0.4 \%$. At this point of the loading history the crack pattern of the spandrel was basically complete. In the following, small stairstepped cracks developed below the support of the timber lintels. In particular the North support of the lintel deteriorated significantly during the cycles with $\theta_{\text {nom }}=1.0 \%$. Most likely due to pull-out forces of the lintel, the bricks supporting the lintel detached from other bricks or broke in two. The test unit failed just before reaching for the first time $\theta_{\text {nom }}=$ $-1.5 \%$ (Figure 11c). Almost simultaneously the North support of the lintel failed and the West horizontal rod fractured. It was not possible to discern which of the two failure mechanisms occurred first. After failure, the spandrel still carried its own weight; the crane support at the right end of the spandrel was not activated (Figure 11c).

TUC featured a shallow masonry arch instead of the timber lintel. Similar to TUA the axial force in the spandrel was kept constant throughout the test but it was doubled to create a failure mode, which was different to that of TUA. To avoid the opening of a gap at the base of the piers, the axial stress in the piers was increased from $0.33 \mathrm{MPa}$ to $0.43 \mathrm{MPa}$ (Table 1). TUC reached its peak shear capacity during the cycles with a nominal rotation of $\theta_{\text {nom }}=0.2 \%$. During these cycles the spandrel failed in shear forming the characteristic X-pattern, which was also observed in real buildings (see Figure 1). Figures 12a and 12b show the crack pattern of TUC for the positive and negative direction of loading, respectively, at a nominal drift of $\theta_{\text {nom }}= \pm 0.4 \%$. For both directions of loading the diagonal shear cracks were the widest cracks, hence indicating a shear failure of the spandrel. Two hinges had formed in the arch, which were located at approximately $1 / 3$ and $2 / 3$ of the span. While the South hinge seemed to be mainly a flexural hinge, the North hinge showed already at $\theta_{\text {nom }}= \pm 0.4 \%$ a significant sliding movement. This was most likely caused by the diagonal crack reaching into the spandrel from the spandrel's South top corner. Unlike the other diagonal crack, it did not point to the corner of the spandrel but ended within this North plastic hinge of the arch. As loading continued the damage to the arch increased with each cycle. The final failure occurred at a drift of $\theta=-3.5 \%$ due to collapse of the arch (Figure 12c).

For TUD a new system concerning the horizontal rods was designed. In principle, the setup was similar to that of TUB, that is, the forces in the horizontal bars were not kept constant by means of a load follower but varied according to the axial elongation of the spandrel. For TUD, however, the horizontal bars consisted of D32 mm Dywidag bars, which were considerably stiffer than the D10 mm threaded rods used for TUB. To straighten the Dywidag bars they were initially prestressed to a force of $\sim 10 \mathrm{kN}$ each. The axial stress in the piers applied by the vertical rods was $0.43 \mathrm{MPa}$ (Table 1). During the cycles with 


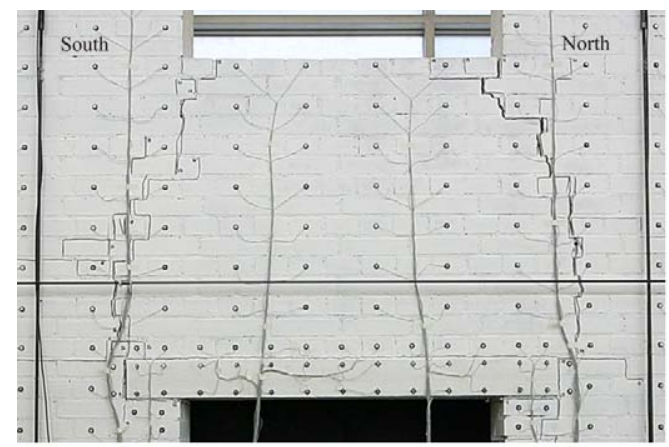

(a)

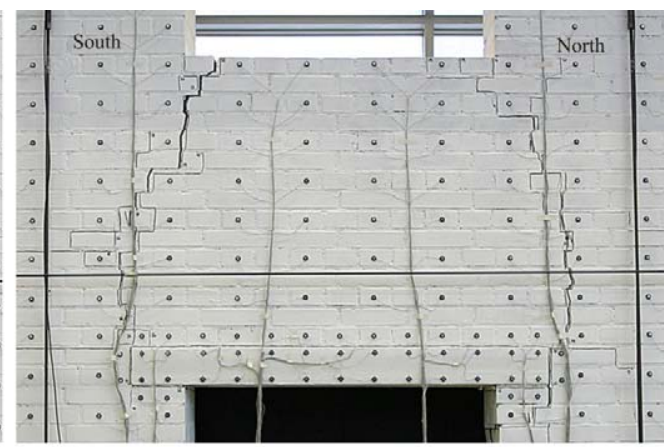

(b)

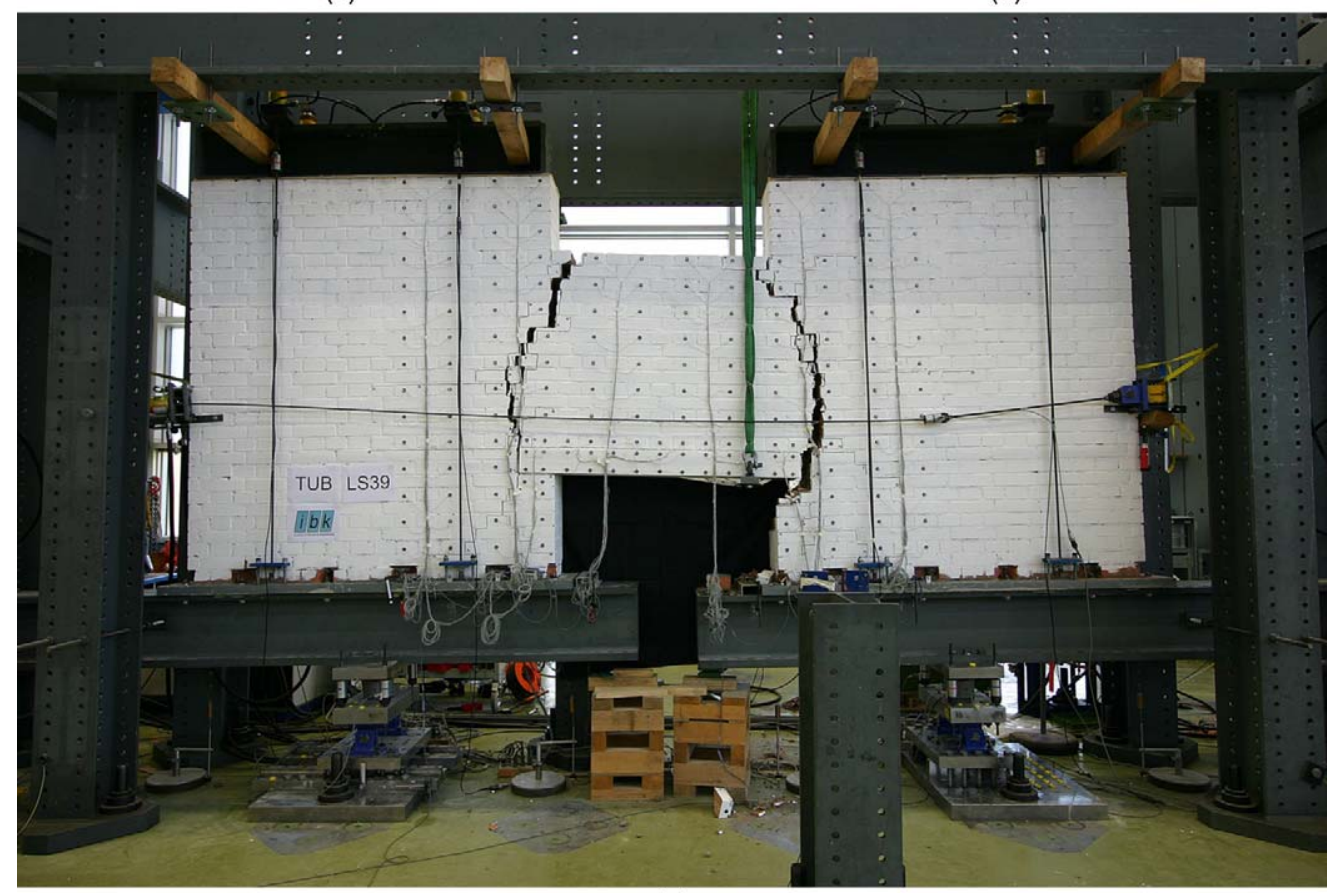

(c)

Figure 11. TUB: Crack pattern at (a) $\operatorname{LS} 22\left(\theta_{\text {nom }}=+0.4 \%\right.$, a), $\operatorname{LS} 23\left(\theta_{\text {nom }}=-0.4 \%, b\right)$ and at LS 39 (failure of TUB at $\theta_{\text {nom }}=-1.5 \%$, c).

$\theta_{\text {nom }}= \pm 0.05 \%$ the first cracks in the masonry arch appeared. As for TUC, these cracks started within the arch at about one and two thirds of the arch length. In the following cycles, a flexural crack pattern developed in the spandrel. Subsequently, diagonal shear cracks formed during the cycles with $\theta_{\text {nom }}= \pm 0.3 \%$. As loading continued the shear cracks dominated more and more the crack pattern, which indicated a shear failure of the spandrel (see Figure 13a and $b$ ). For both directions of loading the damage to the spandrel was concentrated in the upper half of the spandrel while the damage to the arch was at this point still rather 


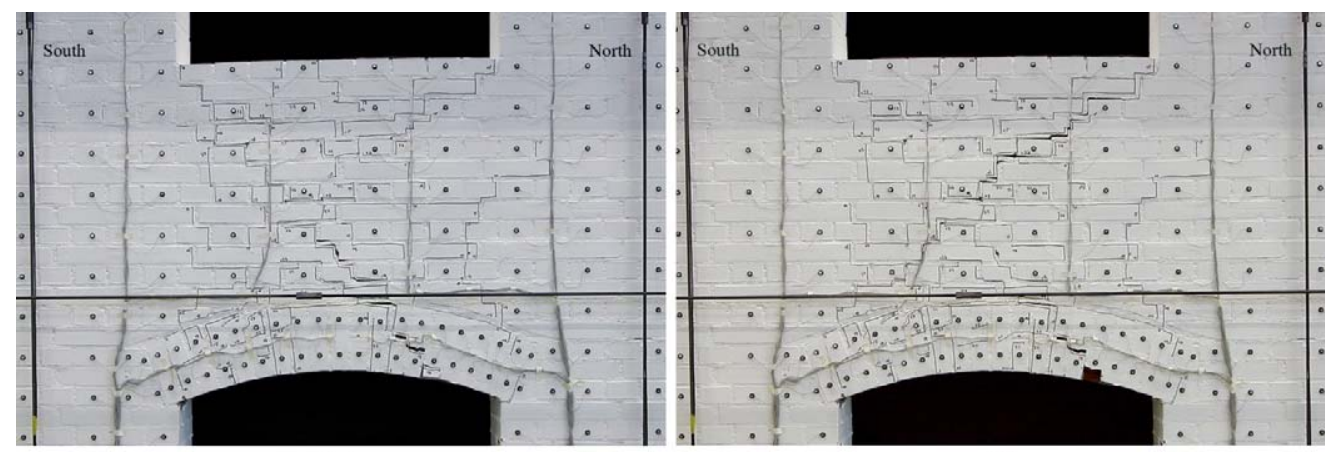

(a)

(b)

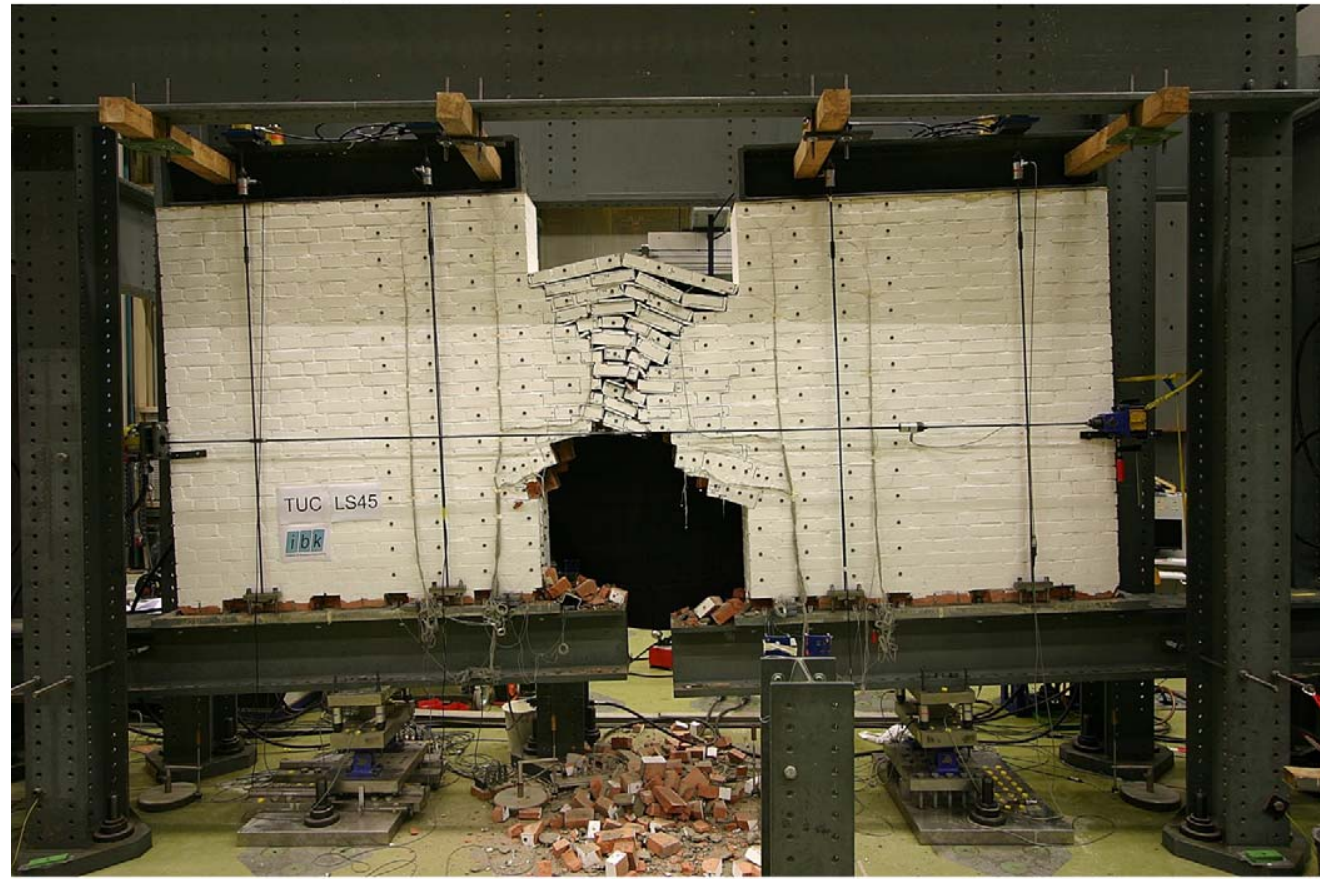

(c)

Figure 12. TUC: Crack pattern at (a) LS $22\left(\theta_{\text {nom }}=+0.4 \%\right)$; (b) LS $23\left(\theta_{\text {nom }}=-0.4 \%\right)$; and at (c) LS 45 (failure of TUC at $\theta=-3.5 \%$ ).

limited. This was probably due to the eccentric horizontal rod, which for drift demands larger than $1.5 \%$ led to a disaggregation of the top part of the spandrel. On the contrary, the limited damage to the lower part of the spandrel and to the arch was due to the rather large force in the horizontal rod. At LS 22 and 23 the axial load in the rod was $85 \mathrm{kN}$ and $74 \mathrm{kN}$, respectively. Starting with the cycles with $\theta_{\text {nom }}= \pm 1.0 \%$, the spandrel and the arch were increasingly damaged and softened. The integrity of the arch suffered in particular due to horizontal cracks running through the bricks of the arch. As a consequence of these horizontal cracks, every 


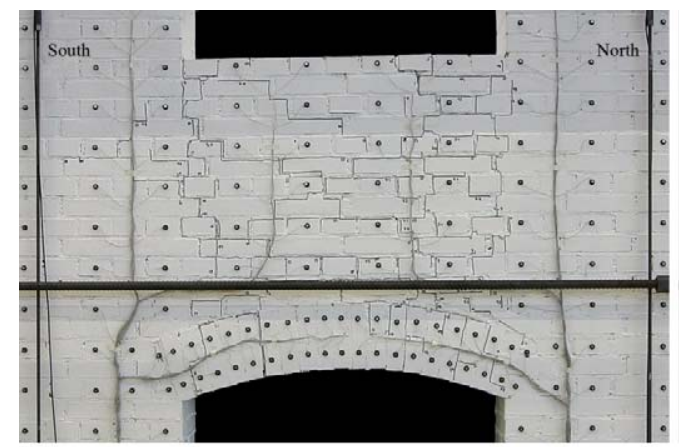

(a)

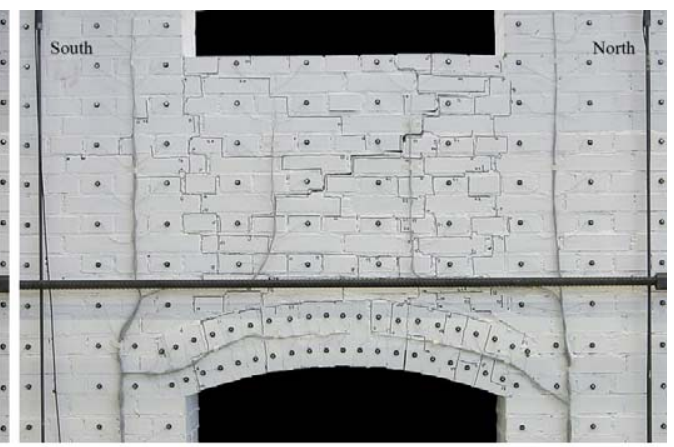

(b)

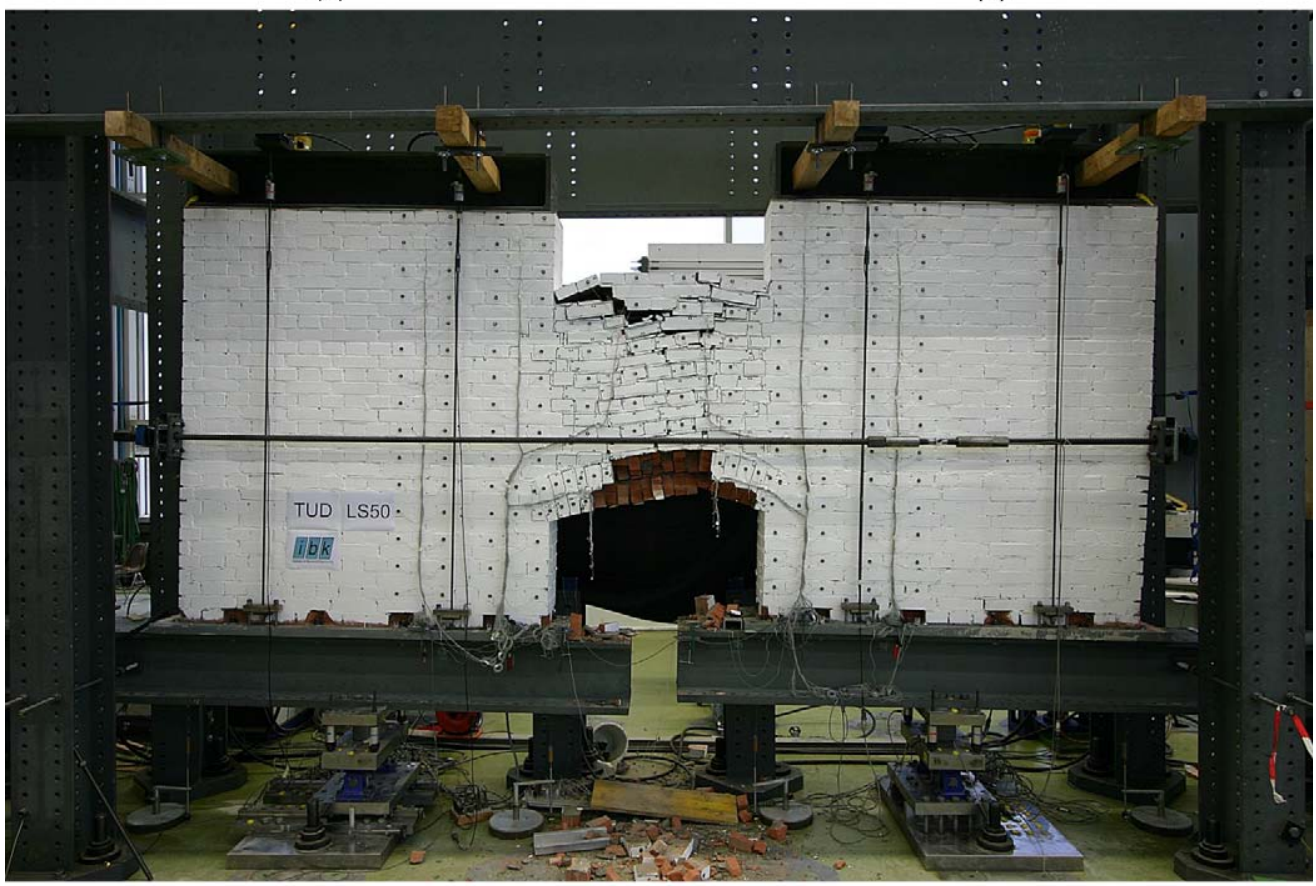

(c)

Figure 13. TUD: Crack pattern at LS $22\left(\theta_{\text {nom }}=+0.4 \%\right.$, a), LS $23\left(\theta_{\text {nom }}=-0.4 \%, \mathrm{~b}\right)$ and at LS 45 (failure of TUD at $\theta=+2.5 \%, \mathrm{c}$ ).

time the loading direction was reversed some lower parts of the bricks fell down. At the end of the test the front row of the central part of the arch collapsed (Figure 13c).

\section{HYSTERETIC BEHAVIOR}

Figures 14 and 15 show the hysteresis curves for the shear force and the axial force in the spandrels, respectively. All masonry spandrels reached their peak resistance at about the same rotation demand. Until the peak resistance was reached, the spandrel remained largely 


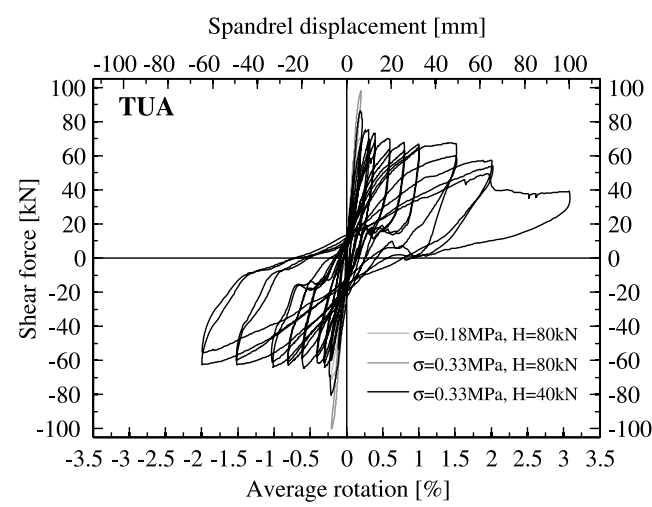

(a)

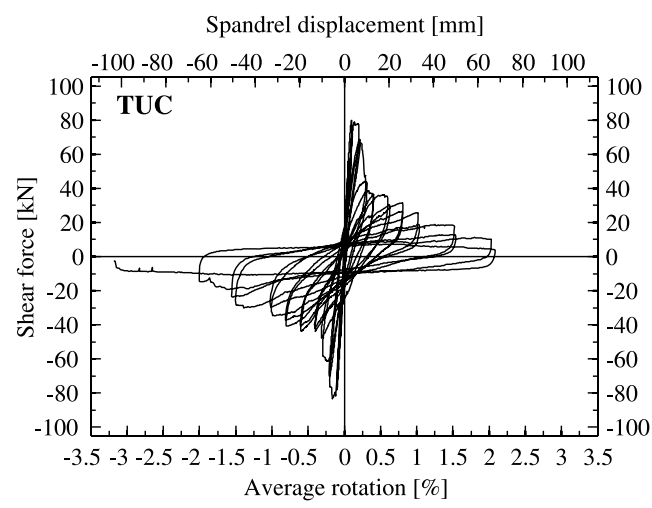

(c)

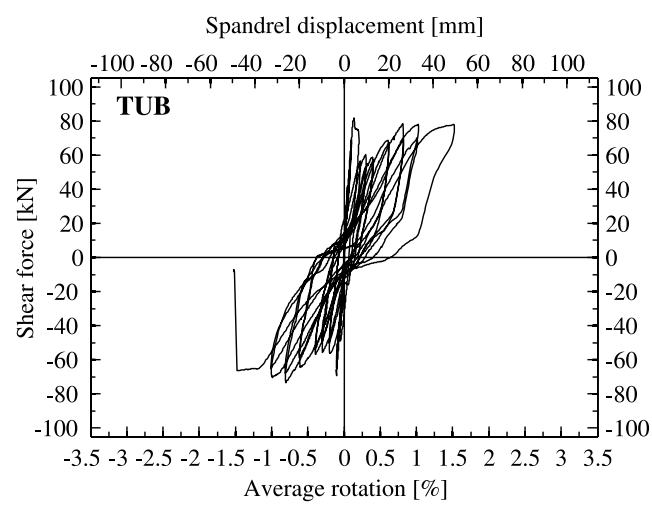

(b)

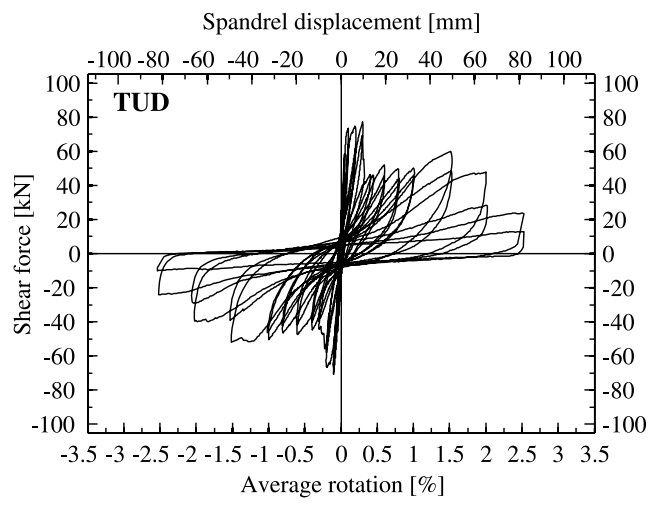

(d)

Figure 14. Spandrel shear force-deformation hysteresis for the test units TUA to TUD.

uncracked. For TUC and TUD, however, the masonry arch developed cracks, which were located at about $1 / 3$ and $2 / 3$ of the span before the peak strength of the masonry spandrel was reached. After the cracking of the spandrel, the shear capacity of the spandrel dropped considerably due to the formation of large shear or flexural cracks in the spandrel.

Once the peak shear force was overcome, the spandrel had the tendency to elongate and the axial restraint on the spandrel played an important role on the overall behavior of the spandrel. The shape of the envelope of the shear force hysteresis depended on the mode of application of the axial load in the spandrel. For TUA and TUC, for which the axial load in the spandrel was kept constant by means of a load follower, the capacity of the spandrel dropped with increasing drift demand.

For TUB and TUD, for which the axial load in the spandrel depended on the axial elongation of the spandrel, an increase in capacity could be observed after the initial drop in strength due to the formation of the first cracks in the spandrel. This increase in shear strength was directly related to the increase in axial force in the spandrel, which is shown in 
Spandrel displacement [mm]

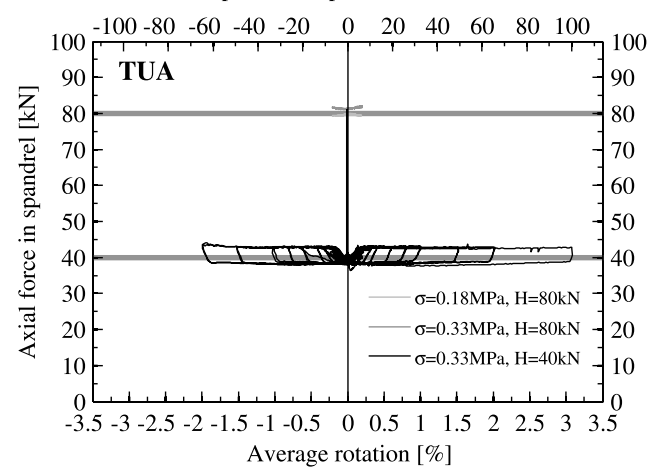

(a)

Spandrel displacement $[\mathrm{mm}]$

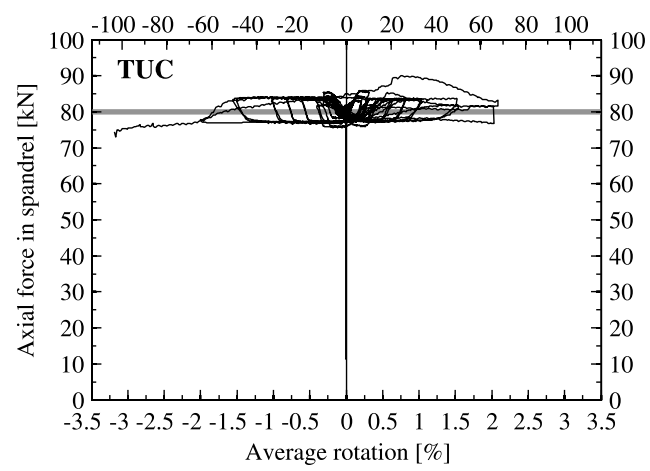

(c)

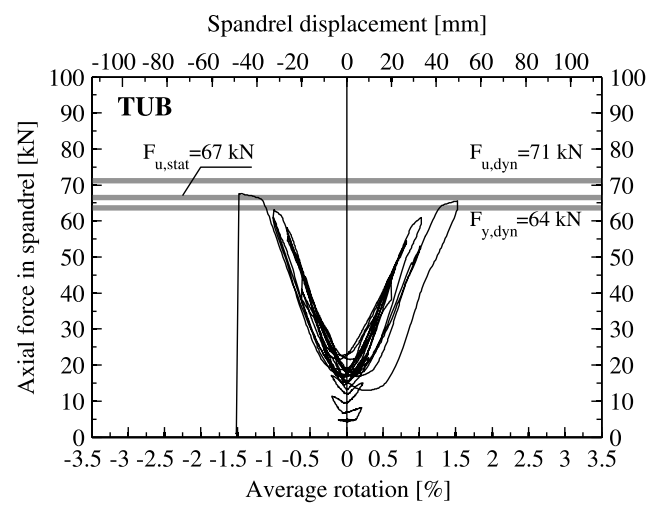

(b)

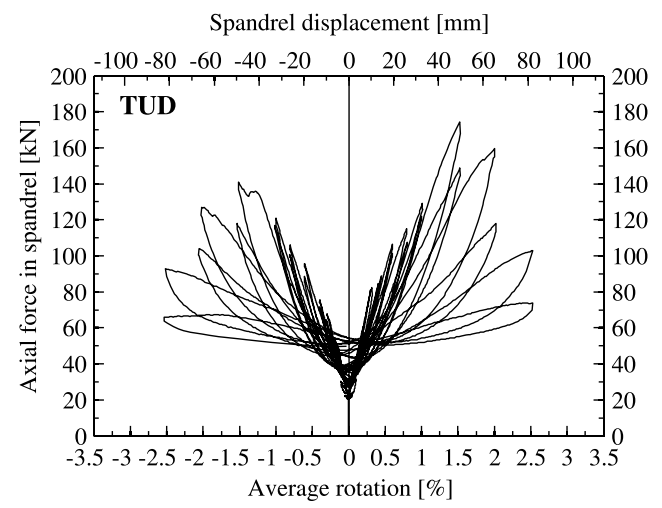

(d)

Figure 15. Hysteresis curves of the axial load in the spandrels of TUA to TUD. Note that for (d) TUD, the curve is plotted at a different scale.

Figures $15 \mathrm{~b}$ and $\mathrm{d}$. As long as the spandrel remained uncracked, the force in the horizontal rods did not change and was virtually equal to the initial post-tensioning force, which was applied to straighten the horizontal bars. The initial post-tensioning forces were $5 \mathrm{kN}$ and $20 \mathrm{kN}$ for TUB and TUD, respectively (Figure $15 \mathrm{~b}$ and $15 \mathrm{~d}$ ). As soon as the spandrel cracked, the force in the horizontal bars increased considerably. The increase was nearly proportional to the rotation applied to the spandrel. It is noteworthy that the axial force in the spandrel at zero rotation tended to increase over the duration of the test suggesting a permanent elongation of the spandrel. The thick grey lines in Figure 15b indicate the yield and tensile strength of the two threaded D10 $\mathrm{mm}$ rods, which were used to apply the horizontal force to TUB. For the cycles of $\theta_{\text {nom }}= \pm 1.5 \%$ the yielding of the horizontal bars is clearly visible. At the end of the test, one of the horizontal bars fractured and the horizontal force dropped to zero.

The bars used for applying an axial force to the spandrel of TUD were so strong that they remained elastic throughout the test. The increase in axial force with rotation was almost linear up to a rotation of $\theta_{\text {nom }}= \pm 1.0 \%$ (Figure $15 \mathrm{~d}$ ). For larger rotations, the 
hysteresis loops of the axial load-rotation relationship turned fatter indicating a strong damage to the masonry spandrel. The axial force dropped for cycles with rotations larger than $\pm 1.5 \%$. For these cycles the damage concentrated more and more in the upper part of the spandrel and in the masonry arch below the horizontal rods. As a consequence, the axial elongation at the height of the rod was therefore smaller than in previous cycles.

Differences in the spandrel shear force-rotation hysteresis (Figure 14) are also noticeable between masonry spandrels with timber lintels (TUA and TUB) and masonry spandrels with shallow arches (TUC and TUD). For the latter the loss in strength was significantly larger than for the spandrels with timber lintels since the timber lintel contributed substantially to the integrity of the spandrel at large rotation demands. When the spandrel was damaged the timber lintel served as a support for loose parts of the spandrel. The masonry arch on the contrary was prone to damage and eventually collapsed for both test units TUC and TUD.

Failure of all four spandrels occurred for significantly greater drift demands than those that are typically associated with the shear and flexural failure of piers. The current European seismic design code proposes for shear and flexural failure of the piers ultimate drift limits of $0.4 \%$ and $0.8 \% H_{0} / D$, respectively, where $H_{0} / D$ is the shear ratio (CEN 2005). The spandrel tests were continued beyond these limits. However, it is recommended to regard these results with caution when transferring them to real applications. This is for two reasons: (i) Possible damage to the piers during real earthquakes might modify the boundary conditions imposed on the spandrel while in the tests the piers remained over the entire range of rotations virtually undamaged; (ii) out-of-plane accelerations might lead to out-of-plane failure of the masonry spandrels once the in-plane loading has disjointed the masonry spandrel (see Figure 2).

\section{STRENGTH OF MASONRY SPANDRELS}

Although experimental evidence was lacking, equations for estimating the peak strength of masonry spandrels have been included in the guideline FEMA 306 (ATC 1998). The following section presents new equations for the peak strength of masonry spandrel. Flexural and shear failure are considered separately and the predicted spandrel strength corresponds to the smaller of the two values. Unlike previous equations in FEMA 306, the proposed equations account explicitly for the contribution of the masonry arch to the peak strength of the spandrel elements.

When the spandrels reached their maximum resistance, they were still largely uncracked. The peak shear resistance of the spandrels can therefore be estimated assuming that the spandrel behaves in its central part as an elastic beam. The shear stress distribution of an elastic, homogenous beam is parabolic over its height. The peak shear strength of a masonry spandrel is therefore:

$$
V_{s h}=\frac{2}{3} \tau_{\max } h_{s p} t_{s p}
$$

where $\tau_{\max }$ is the maximum shear stress, $h_{s p}$ the height of the spandrel and $t_{s p}$ the thickness of the spandrel. The maximum shear stress $\tau_{\max }$ at midspan can be approximated by the peak shear strength of the joints for a mean axial stress of $H_{s p} / h_{s p} t_{s p}$ where $H_{s p}$ is the horizontal force applied to the spandrel (Table 4). 
The flexural peak strength can be roughly estimated from the tensile strength of the head joints and the interlock of the bed joints. The tensile strength of the head joints is estimated using the parabolic tension cut-off criterion for mortar joints proposed by Rots and Lourenço (1993). The tensile strength of this joint is therefore $f_{h j, p e a k}=\frac{c_{p e a k}}{2 \cdot \mu_{p e a k}}$ :

$$
f_{\text {hj,peak }}=\frac{c_{\text {peak }}}{2 \mu_{\text {peak }}} .
$$

The interlock of the bed joints can be estimated using the principles outlined in FEMA 306 (ATC 1998) and Cattari and Lagomarsino (2008) as:

$$
f_{\text {bj,peak }}=\left(\mu_{\text {peak }} \gamma_{1} \sigma_{\text {pier }}+c_{\text {peak }}\right) \frac{l_{b}}{2\left(h_{b}+h_{j}\right)}
$$

where $l_{b}$ the smaller dimension of the brick $(120 \mathrm{~mm})$ and $h_{b}+h_{j}$ the average thickness of a brick and a bed joint ( $74 \mathrm{~mm}$ for the tested spandrels). The stress $\gamma_{1} \sigma_{\text {pier }}$ is the average vertical stress on a bed joint at the spandrel end, that is, at the location of the vertical crack. The factor $\gamma_{1}$ is assumed as 0.5 (ATC 1998). The total equivalent tensile strength of the uncracked spandrel can be computed as the sum of the tensile strength of the head and bed joints:

$$
f_{t, p e a k}=f_{h j, p e a k}+f_{b j, p e a k} .
$$

Assuming a linear stress distribution over the height of the spandrel, the peak moment for which a maximum stress of $f_{t, p e a k}$ is obtained, can be calculated as follows:

$$
M_{f l}=\left(f_{t, p e a k}+\frac{H_{s p}}{h_{s p} t_{s p}}\right) \frac{h_{s p}^{2} t_{s p}}{6}-H_{s p} e_{H_{s p}}
$$

where $e_{H s p}$ is the eccentricity of the horizontal force $H_{s p}$ applied to the spandrel from the centre line of the spandrel $(165 \mathrm{~mm})$. For TUB and TUD, for which the horizontal force varied, $H_{s p}$ at peak strength was $5 \mathrm{kN}$ and $81 \mathrm{kN}$ for TUB and TUD, respectively. The peak shear force of the spandrel can hence be estimated as:

$$
V_{f l}=\frac{2 M_{f l}}{l_{s p}}
$$

where $l_{s p}$ is the length of the spandrel.

For TUC and TUD it was observed that the masonry arch cracked before the masonry spandrel and therefore before the peak strength was reached. The arch formed a hinge at 1/3 of the span indicating that an inclined compression strut in the arch contributed to the shear resistance of the spandrel element. The shear strength of the masonry arch can be estimated as:

$$
V_{\text {arch }}=H_{s p} \frac{h_{\text {arch }}}{2 / 3 l_{s p}}
$$


Table 5. Peak strength of masonry spandrels: Comparison of predicted and experimental results

\begin{tabular}{lcccccc}
\hline \hline Test units & $H_{s p}[\mathrm{kN}]$ & $V_{f l}[\mathrm{kN}]$ & $V_{s h}[\mathrm{kN}]$ & $V_{\text {pred }}[\mathrm{kN}]$ & $V_{\text {exp }}[\mathrm{kN}]$ & $V_{\text {pred }} / V_{\text {exp }}[-]$ \\
\hline TUA & 82 & 85 & 146 & 85 & 100 & 0.85 \\
TUB & 5 & 81 & 102 & 81 & 82 & 0.99 \\
TUC & 84 & 83 & 80 & 80 & 83 & 0.96 \\
TUD & 81 & 82 & 79 & 79 & 77 & 1.03 \\
\hline \hline
\end{tabular}

where $h_{\text {arch }}$ is the height of the top of the arch at $1 / 3$ of the span, which is approximately the arch rise plus the thickness of the arch $(120+250=270 \mathrm{~mm}$, see Table 1). For the spandrels with a masonry arch, it was therefore assumed that the axial force passes through the arch rather than the spandrel above the arch. For this reason, Equation (9) was modified to:

$$
M_{f l 2}=f_{t, p e a k} \frac{h_{s p}^{2} t_{s p}}{6}
$$

The shear strength of spandrels with a masonry arch that are associated with flexural failure or shear failure, respectively, are therefore:

$$
\begin{gathered}
V_{f l 2}=V_{a r c h}+\frac{2 M_{f l 2}}{l_{s p}} \\
V_{s h 2}=V_{a r c h}+V_{s h} .
\end{gathered}
$$

Table 5 summarizes the axial force $H_{s p}$ of the spandrel, which was acting on the spandrel at the moment when the peak shear strength was attained as well as the predicted flexural strength $\left(V_{f l}\right)$ and predicted shear strength $\left(V_{s h}\right)$ of the masonry spandrels. The predicted spandrel strength $V_{\text {pred }}$ corresponds to the smaller value of $V_{f l}$ and $V_{s h}$ and is compared to the peak experimental strength $V_{\text {exp }}$. The proposed equations show a very good agreement with the experimental results in terms of the predicted peak strength. The mean value of the ratio of predicted-to-observed strength is 0.96 .

\section{CONCLUSIONS}

The four quasi-static cyclic tests presented in this paper provide force-deformation characteristics of masonry spandrels with either timber lintels or masonry arches. The failure mechanisms that were obtained for TUA to TUD corresponded well to those that were observed for spandrels after the earthquake in L'Aquila. TUB failed in flexure and TUC in shear. TUA and TUD developed first flexural cracks and later shear cracks. The final failure mode of TUA was a mixed flexure-shear mode while for TUD the shear cracks dominated the behavior. In general, spandrels with small axial loads were prone to flexural failure and spandrels with large axial loads prone to shear failure. This also agrees with the observations after the earthquake in L'Aquila. In the last part of the paper, equations for predicting 
the peak strength of masonry spandrels failing in flexure or shear were presented. The equations are based on simple mechanics and estimate the observed peak strengths of the spandrel elements rather well.

\section{ACKNOWLEDGMENTS}

Funding for this work was provided by the KGV Prevention Foundation in the framework of the research project "Nonlinear deformation behavior of unreinforced masonry structures through testing and numerical simulations." The tests were performed in the laboratory of the Institute of Structural Engineering at the ETH Zurich (Switzerland), where Dominik Werne, Thomas Jaggi, and Christoph Gisler supported the authors during testing. All contributions are gratefully acknowledged.

\section{REFERENCES}

Applied Technology Council (ATC), 1998. FEMA 306: Evaluation of earthquake damaged concrete and masonry wall buildings, Basic Procedures Manual, ATC-43 Project, Washington D.C.

Beyer, K., Abo-El-Ezz, A., and Dazio, A., 2010. Quasi-Static Cyclic Tests on Different Types of Masonry Spandrels, IBK Report No 327, Institute of Structural Engineering, ETH Zürich, Switzerland.

Binda, L., Mirabella, G., Tiraboschi, C., and Abbaneo, S., 1994. Measuring masonry material properties, in Proceedings of the U.S.-Italy Workshop on Guidelines for Seismic Evaluation and Rehabilitation of Unreinforced Masonry Buildings, University of Pavia, Italy, p. 6-36-24.

Cattari, S., and Lagomarsino, S., 2008. A strength criterion for the flexural behavior of spandrels in un-reinforced masonry walls, in Proceedings, $14^{\text {th }}$ World Conference on Earthquake Engineering, Beijing, China.

Dazio, A., Beyer, K., Braune, F., Fritsche, S., and Mittax, X., 2009. Das $M_{w}=6.3$ Erdbeben von L'Aquila am 6. April 2009 (The $M_{w}=6.3$ L'Aquila Earthquake on 6 April 2009), Report of the April 15-18 SGEB Reconnaissance Mission, Swiss Society for Earthquake Engineering and Structural Dynamics, Zürich, Switzerland, available at http://www.sgeb.ch/ erkundungsmissionen/Aquila.pdf.

European Committee for Standardization (CEN), 2005. Eurocode 8: Design of structures for earthquake resistance - Part 3: General rules, seismic actions and rules for buildings, Design Code EN 1998-3, European Committee for Standardization, Brussels, Belgium.

European Committee for Standardization (CEN), 2006a. EN 1015-11: Methods of test for mortar for masonry: Determination of flexural and compressive strength of hardened mortar, European Committee for Standardization, Brussels, Belgium.

European Committee for Standardization (CEN), 2006b. EN 12390-1: Steel for the reinforcement and prestressing of concrete - Test methods - Part 1: Reinforcing bars, wire rods and wire. European Committee for Standardization, Brussels, Belgium.

European Committee for Standardization (CEN), 2007. EN 1052-3: Methods of test for masonry Part 3: Determination of initial shear strength, European Committee for Standardization, Brussels, Belgium.

Gattesco, N., Clemente, I., Macorini, L., and Noè, S., 2008. Experimental investigation of the behavior of spandrels in ancient masonry buildings, in Proceedings, $14^{\text {th }}$ World Conference on Earthquake Engineering, Beijing, China. 
Graziotti, F., Magenes, G., and Penna, A., 2009. Progetto di una sperimentazione su elementi di fascia muraria, Rapporto Reluis, Allegato 4.3-UR01-1, Università di Pavia e EUCENTRE, Pavia, Italy.

Milani, G., Beyer, K., and Dazio, A., 2009. Upper bound limit analysis of meso-mechanical spandrel models for the pushover analysis of 2-D masonry frames, Engineering Structures 31, 2696-2710.

Rots, J. G., and Lourenço, P. B., 1993. Fracture simulations of masonry using non-linear interface elements, in Proceedings, $6^{\text {th }}$ North American Masonry Conference, Philadelphia, PA.

(Received 20 July 2010; accepted 25 October 2011) 